\title{
GÊNERO E FAMÍLIA EM UMA SOCIEDADE JUSTA: ADESÃO E CRÍTICA À IMPARCIALIDADE NO DEBATE CONTEMPORÂNEO SOBRE JUSTIÇA ${ }^{1}$
}

\author{
Flávia Biroli
}

\section{RESUMO}

O artigo analisa o debate sobre justiça e suas implicações para a crítica feminista. O foco está na discussão sobre a necessidade de um ponto de vista imparcial para a produção de critérios de justiça nas obras de John Rawls e Susan Okin. A crítica e a adesão de Okin à abordagem de Rawls envolvem a defesa, pela autora, da conciliação entre o recurso à imparcialidade e a crítica feminista, em busca de relações de gênero mais justas. Em Rawls, a justiça depende da suspensão de interesses e afetos ligados às diferentes posições dos individuos na estrutura social e do desinteresse mútuo, juntamente com a falta de conhecimento da própria posição. Para Okin, o recurso à imparcialidade não exclui a empatia, a consideração das diferenças e o cuidado com os outros. Expostas essas posições, o artigo discute criticamente o valor da imparcialidade e conclui que a adesão aos pressupostos liberais restringe o potencial de uma teoria feminista da justiça.

PALAVRAS-CHAVE: justiça; gênero; família; liberalismo; teoria feminista; imparcialidade.

"Reduzir as mulheres à sua 'humanidade'é tão opressivo e teoricamente insatisfatório quanto reduzi-las à sua feminilidade" ${ }^{2}$.

(MOI, 1999, p. 8).

\section{INTRODUÇÃO}

Em Léxico familiar, de 1963, a escritora italiana Natalia Ginzburg apresenta uma apreciação afetiva de suas origens familiares e das personagens mais centrais de sua vida. $\mathrm{O}$ que cativa nessa narrativa é, entre outras coisas, a maneira como a autora expõe a indissociabilidade entre sua trajetória e as características das relações entre sua mãe, seu pai e seus irmãos. Os hábitos e valores familiares, cristalizados em situações que não teriam qualquer importância para alguém que não compartilhasse o ambiente em que se reproduziam, aparecem em uma combinação fina de ironia, admiração e amor.

\footnotetext{
1 A discussão presente neste artigo foi possível a partir do trabalho na pesquisa "Gênero e política na mídia brasileira", financiada pelo Conselho Nacional de Desenvolvimento Científico e Tecnológico (CNPq). Agradeço a Luis Felipe Miguel pelo diálogo, fundamental para o desenvolvimento das reflexões aqui presentes, e pelos comentários a uma versão preliminar deste artigo.
}

Nesse relato, a monotonia da vida da mãe, que se alterna entre atividades que preenchem seu tempo - o cuidado com filhos e netos, a preocupação com as roupas e a aparência, as interações com funcionárias domésticas e o aprendizado do russo - é apresentada juntamente com as características da vida do pai, como professor universitário com posição contrária ao fascismo, envolvido com a própria profissão, com a paixão pelas montanhas e pelo esqui e com a vida familiar. Em uma passagem, Paola, irmã de Natalia, questiona a inquietude e o ciúme que a mãe sente por ela, comparando-a à sogra, que "passa os dias bordando", e ouve a seguinte resposta: "O que é que eu posso fazer, se não sou surda como a sua sogra? Eu me chateio de ficar sempre fechada em casa! Tenho vontade de passear! Imagine só se aprendo a bor-

2 Trecho original: "It is as oppressive and theoretically unsatisfactory to reduce women to their 'general humanity' as it is to reduce them to their femininity". Em todo o artigo, as versões em português de trechos das obras em língua estrangeira são de responsabilidade da autora. 
dar! Não sou disso! Não sei dar ponto! Quando remendo as meias do papai, faço uns pontos horríveis, que depois Natalia tem que desmanchar!" (GINZBURG, 1988, p. 141). Antes, em outra passagem, o gosto da mãe pelo cinema aparece juntamente com a reação do pai, quando chegava do trabalho e não a encontrava: "Por onde diabos você andou? berrava meu pai. Estava ficando preocupado! Aposto que foi ao cinema hoje também! Você passa a vida no cinema!” (idem, p. 90).

A coexistência entre um padrão de gênero historicamente constituído - a divisão sexual do trabalho, com suas consequências para as oportunidades abertas a mulheres e homens - e as características que tornam os indivíduos e suas relações tão específicas, indica a complexidade da análise da família como parte do problema da justiça social. Pode-se dizer que a família é produto de, e reproduz ativamente, relações de poder historicamente estruturadas, sem deixar de ser um ambiente central à definição das especificidades dos indivíduos e dos valores e atitudes, racionais e afetivos, que terão impacto sobre sua participação em outras esferas da vida. Pode-se assumir, deixando variações em suspenso por enquanto, que de um ponto de vista feminista a análise da família impõe a confrontação de relações de gênero assimétricas, das quais se extrai boa parte do entendimento que temos sobre as diferenças entre os papéis de homens e mulheres na sociedade, e não apenas na esfera familiar. Mas essa confrontação não exclui a consideração de que existe uma correlação desejável entre a intimidade e a autonomia dos indivíduos para definir quais arranjos lhes parecem mais pertinentes, e como serão vividas suas relações afetivas e organizada sua rotina doméstica.

As respostas a essa complexidade variam bastante, mesmo quando se restringe a investigação ao âmbito da teoria feminista. De maneira esquemática, as posições variam entre um pólo em que as relações familiares são, necessariamente, o equivalente a uma estrutura de gênero injusta e violenta (levando, no limite, à defesa da abolição da família) e outro em que as relações de cuidado que estão no centro da vida familiar são tomadas como a expressão de valores morais e éticos à parte, que deveriam ser valorizados. $\mathrm{Na}$ teoria política - e na teoria da justiça -, de maneira mais abrangente, no entanto, predomina uma alternativa: o silêncio quanto às relações de poder $n a$ família. Isso significa que mesmo quando a família é entendida como instituição central à socialização dos indivíduos e, como tal, à definição das relações e valores que organizam uma dada sociedade, o problema de como as relações intra-familiares estabelecem-se, assim como sua conexão com as relações de poder em outras esferas, permanece negligenciado.

Este artigo trata da relação entre família e justiça a partir do diálogo entre as abordagens de dois filósofos políticos estadunidenses, Susan Moller Okin e John Rawls. Trata-se de um diálogo por duas razões. Em primeiro lugar, porque é objetivo deste artigo colocar em discussão as diferenças e continuidades entre suas abordagens. O diálogo é, portanto, produzido pela discussão aqui proposta. Mas também porque Okin e Rawls, em suas obras, consideraram as abordagens de uma e outro em momentos específicos de sua discussão. No caso de Okin, a crítica e a apreciação positiva de conceitos importantes da teoria da justiça em John Rawls é central a sua posição sobre a conexão entre família e justiça. Rawls, por sua vez, discutiu as críticas a ele feitas por Susan Okin no livro Justice, Gender and the Family, de 1989. O diálogo com Okin o levou a ampliar (ainda que pouco) as considerações escassas sobre a família presentes no livro Uma teoria da Justiça, publicado pela primeira vez em 1971, na discussão que apresenta no livro Justiça como eqüidade: uma reformulação, publicação de 2002 que retoma palestras proferidas em Harvard durante a década de 1980.

Cabe a ressalva de que esta não pretende ser uma discussão ampla sobre o problema da família nas teorias da justiça, nem pretende explorar a obra de John Rawls para além do problema específico de como conceitos e proposições centrais a sua abordagem abrem possibilidades (ou impõem obstáculos) para compreender as relações entre família e justiça. Como a obra de Rawls é, certamente, uma das que mais exerceram impacto sobre a teoria política nas últimas décadas, a escolha da "reação" de Susan Okin às suas posições atende a um foco bastante específico: o de explicitar, nesse caso, as possibilidades e os limites de uma crítica feminista que expõe as assimetrias de gênero como uma questão central à justiça, ao mesmo tempo em que adere a algumas das premissas centrais às teorias liberais da justiça. Refiro-me à adesão à imparcialidade e à universalidade como valores adequados para a defesa de relações sociais mais justas. 
O foco restrito da análise não impede, no entanto, que ela contribua para a reflexão sobre alguns problemas de caráter amplo, que têm sido destacados nos debates contemporâneos no campo da teoria política feminista. Menciono dois, pela importância que têm para a abordagem assumida neste artigo. O primeiro diz respeito às especificidades do "feminino" e do "masculino" e à consideração dessas especificidades para a promoção de uma sociedade democrática, justa e inclusiva. Simplificando um problema complexo, relaciona-se à alternativa entre valorizar o que seria específico das experiências de mulheres e homens e, portanto, suas diferenças, ou ter como meta a superação das diferenças de gênero, tornando o sexo potencialmente indiferente na definição das oportunidades e das escolhas dos indivíduos. Como se verá mais adiante, a posição de Susan Okin aproxima-se desta última e recorre, para fundamentá-la e situá-la no debate sobre justiça, a alguns conceitos-chave na obra de John Rawls.

O segundo problema está diretamente relacionado ao primeiro e pode ser colocado, neste momento, como uma questão: a adesão aos valores liberais da imparcialidade e da universalidade impõe limites restritivos à crítica feminista? Um dos aspectos aqui considerados é, assim, se a imparcialidade e a universalidade são recursos necessários para atingir critérios de justiça entendidos como adequados de uma perspectiva feminista. Por outro lado, fundada no valor da neutralidade, e na defesa de instituições que sejam neutras em relação às diversas concepções do bem, a análise dos problemas de gênero permite enfrentar as formas de marginalização e dominação que têm impacto sobre as mulheres nas sociedades contemporâneas organizadas por valores liberais?

$\mathrm{O}$ artigo divide-se em três seções, além desta introdução. A primeira seção apresenta as posições centrais de Okin sobre a relação entre família e justiça, discutindo os principais aspectos de sua crítica e seu entendimento dos problemas da justiça na família. As abordagens da família em John Rawls são, nesse mesmo capítulo, discutidas em diálogo com as posições assumidas por Okin. Está no centro dessa discussão a análise crítica dos desdobramentos da divisão sexual do trabalho doméstico para a participação das mulheres em outras esferas da vida. O problema da vulnerabilidade das mulheres em sociedades estruturadas pelas diferenças de gênero, central à análise de Okin, permite considerar a oposição entre o público e o privado como um dispositivo de reprodução da dominação.

A segunda seção discute a defesa, feita por Okin, do artifício da "posição original" na obra de John Rawls, mais especificamente em Uma teoria da Justiça, de 1971. Para a autora, é possível (e desejável) uma adequação parcial desse conceito em uma crítica feminista da justiça, destacando a empatia entre diferentes indivíduos na produção dos princípios de justiça. A seção procura, ainda, elucidar o sentido da defesa, feita por Okin, de que uma sociedade justa exige a superação do gênero. A última seção apresenta, por fim, uma breve conclusão, crítica à adesão de Susan Okin aos valores liberais da imparcialidade e da universalidade. Neste ponto, o artigo sustenta que uma crítica feminista efetiva depende, hoje, da confrontação com alguns dos principais pilares do liberalismo, entre eles a noção de imparcialidade. A posição específica, relacional, ocupada por indivíduos e grupos em uma dada estrutura social deve ser a matéria concreta de que se constitui o debate sobre justiça. Mas isso exige considerar de maneira adequada um problema levantado pela própria Okin ao discutir as posições comunitaristas e tradicionalistas: o específico não está livre de relações de dominação que constituem as posições e os valores a elas associados.

\section{GÊNERO, FAMÍLIA E INJUSTIÇA}

A divisão entre público e privado é estruturante da política e do pensamento político ao menos desde o século XVII e permanece, como um pressuposto não problematizado, nas correntes hegemônicas da teoria política contemporânea. A crítica feminista estabeleceu conexões entre a subordinação das mulheres aos homens e a definição dos papéis de umas e outros nas diferentes esferas sociais. Nas sociedades burguesas, a antinomia entre liberdade civil e sujeição corresponderia à dualidade entre a esfera pública e a esfera privada (PATEMAN, 1993). As ambiguidades nos sentidos assumidos pelos termos dessa dualidade são apontadas por diversas autoras, que expõem a oscilação, nas vertentes hegemônicas da teoria política, das oposições entre Estado e sociedade e entre vida doméstica e vida não-doméstica, incluindo o âmbito econômico em uma ou outra dessas esferas (MACKINNON, 1989; PATEMAN, 1989). 
Há, entre as perspectivas que fazem parte dessa crítica, o reconhecimento de que os laços entre as mulheres e a domesticidade, que incluem o cuidado com as crianças e outros familiares, foram produzidos historicamente. Mesmo que os desdobramentos dessa constatação sejam variados, ela orienta a análise crítica dos processos históricos que produziram uma forma específica de valorização da maternidade, atando a mulher a esse papel ${ }^{3}$. Orienta, também, a crítica à teoria política hegemônica, sobretudo ao contratualismo moderno, que participou da definição do conceito de indivíduo no Ocidente ${ }^{4}$, assim como a crítica à racionalidade e à impessoalidade como valoresguia da esfera pública contraposta à esfera privada, que seria, então, o lugar dos afetos e das especificidades 5 .

Por outro lado, o silêncio relativo aos problemas de gênero na maior parte dos debates sobre justiça impede a compreensão dos impactos diferenciados da "proteção" e do "sigilo" para a garantia da intimidade. O problema da definição dos limites para a ação do Estado no âmbito doméstico varia se a avaliação das fronteiras é feita a partir da experiência histórica de homens ou de mulheres. Se, para alguns, essa garantia significa a preservação da individualidade e das relações afetivas, produzindo espaço e tempo necessários ao desenvolvimento de suas potencialidades, para outros - mais especificamente, para outras - pode significar a preservação de um espaço em que relações assimétricas, e mesmo violentas, e a imposição de determinadas rotinas impedem a afirmação da individualidade e estabelecem os limites ambíguos entre habilidades socialmente estimuladas, aceitas e reconhecidas e comportamentos (e identidades) socialmente desvalorizados. Em parte relevante das análises feministas, isso não significa uma defesa da dissolução das diferenças entre as esferas (OKIN, 1989a; PATEMAN, 1989). Não significa, também, que se ignore o sentido que o espaço doméstico e privado tem na construção da identidade de homens e mulheres, considerando, ao mesmo tempo, a crítica à romantização do lar e a defesa da relevância desse espa-

\footnotetext{
3 Como em Badinter (1985) e Beauvoir (2008).

4 Como em Okin (1979), Elshtain (1981) e Pateman (1993).

5 Também presente em Elshtain (1981), Sarah Ruddick (1989) e Carol Gilligan (1982), constituindo o "pensamento maternal".
}

ço para a identidade individual e coletiva (COHEN, 1997; YOUNG, 2005). Defender o valor da privacidade não significa deixar os indivíduos entregues a sua própria sorte. $\mathrm{O}$ conceito de privacidade defendido por Jean Cohen, por exemplo, relaciona o exercício da autonomia a um processo criativo que exige a preservação de espaços de si (a partir da noção de "territories of the self", de Erving Goffman (2010)) para a produção das identidades, frágeis e individualizadas ${ }^{6}$.

Carole Pateman (1989, p. 119) estabelece uma relação entre a confrontação com a oposição entre o público e o privado e a maior ou menor acomodação da crítica feminista ao liberalismo. Uma maior acomodação aos pressupostos liberais significaria uma menor confrontação com essa dualidade. Haveria, assim, pelo menos duas vertentes representativas dessas análises. Uma delas corresponde à defesa da ampliação dos direitos da mulher, produzindo uma universalização efetiva, que as inclua. Neste caso, o liberalismo é alvo de críticas, mas por não realizar de fato suas promessas de inclusão. Ficam, assim, mantidas algumas de suas premissas, entre elas as noções de universalidade e neutralidade como recursos adequados para promover a inclusão. $\mathrm{Na}$ segunda vertente, estariam as críticas que rejeitam a dualidade entre o público e o privado, tal como é definida pelo liberalismo. Para estas, está em questão o caráter patriarcal do liberalismo. A definição de uma posição subordinada e marginal para as mulheres não corresponde a falhas ou incompletudes, mas à sua própria estrutura.

A posição de Susan Okin não se encaixa facilmente a nenhuma das duas vertentes mencionadas acima, propostas por Pateman para explicar as variações na teoria feminista, em sua maior ou menor aproximação ao liberalismo. A crítica à

\footnotetext{
6 Vale acrescentar que existem impedimentos específicos para a preservação desses espaços para as mulheres, em famílias com estrutura convencional de gênero. Susan Okin (1998) contrapõe as noções da intimidade como espaço para o desenvolvimento dos afetos à vulnerabilidade de mulheres e crianças à violência e à dominação no espaço doméstico; da intimidade como "retirada das máscaras" à ausência de privacidade para as mulheres quando a divisão sexual do trabalho é convencional e elas têm poucas oportunidades para distanciar-se do papel de mãe; da intimidade como a solidão necessária ao auto-desenvolvimento à expectativa de que as mulheres doem seu tempo para os filhos e a vida doméstica.
} 
dicotomia entre o público e o privado é central aos argumentos da autora (OKIN, 1979; 1989a; 1998). O público e o privado são vistos como partes interligadas de um ciclo de desigualdades entre os sexos (OKIN, 1989a, p. 133), o que tem implicações para a análise das tradições e abordagens teóricas: "a maior parte das teorias angloamericanas da justiça é, em grande medida, sobre homens com mulheres em casa" (idem, p. 110). Apesar disso, sua adesão às premissas do liberalismo é evidente. Em suas análises da teoria da justiça em John Rawls sobressai o entendimento de que a "posição original" e o "véu da ignorância", dispositivos que permitiriam abstrair as especificidades dos indivíduos para a definição adequada dos critérios de justiça, são compatíveis com a crítica feminista. De maneira simplificada, a defesa de que a suspensão das especificidades dos indivíduos é necessária à produção de normas equitativas é central ao liberalismo e é um pivô na teoria da "justiça como equidade", em John Rawls. A próxima seção do artigo será dedicada a esse tópico. Neste momento, ele contribui para identificar, na abordagem de Okin, a presença simultânea, de um lado, de uma análise da família centrada na confrontação com a configuração liberal da oposição entre o público e o privado e, de outro, de uma abordagem que pressupõe que a conexão entre imparcialidade e justiça é necessária para a produção da igualdade de gênero.

A crítica aos teóricos do comunitarismo (idem) e do multiculturalismo (OKIN, 1999) também expõe essa tensão. A análise dos comunitaristas e do recurso à "tradição", que trata especialmente de Alasdair MacIntyre e Michael Walzer, explicita aspectos dos argumentos da autora que são relevantes para esta discussão. Ainda que as críticas mais centrais sejam dirigidas ao conservadorismo presente na abordagem de MacIntyre, as preocupações de Okin estendem-se ao recurso à tradição, de modo mais geral. O principal problema está no fato de que a tradição e os "significados compartilhados" de comunidades e culturas são definidos a partir de determinadas perspectivas em geral, as daqueles que ocupam os degraus mais altos nas hierarquias internas aos grupos. A desconsideração das hierarquias e conflitos internos aos grupos significa, assim, a desconsideração de problemas relevantes para a definição do que é justo. Questões relativas à dominação social, às quais voltaremos na última seção deste artigo, não seriam consideradas de maneira adequada pelos comunitaristas. A idéia de que a preservação das tradições é a expressão dos interesses de toda uma comunidade esbarra no fato de que os mais vulneráveis podem não ter nem mesmo as ferramentas para a crítica aos valores que legitimam sua submissão. Nas palavras da autora, "aqueles a quem as estruturas de casta, de classe, de raça ou de gênero negam educação têm muito menos chances de adquirir as ferramentas para se expressar de maneiras que sejam publicamente reconhecidas" e, portanto, para interpretar os significados compartilhados de modo a transformálos em crítica social (OKIN, 1989a, p. 67).

Mais tarde, ao discutir o que vê como incompatibilidades entre o feminismo e o multiculturalismo (OKIN, 1999), Okin voltaria a alguns dos argumentos presentes em Justice, Gender and the Family para afirmar, sobretudo, que a defesa da identidade cultural de grupos específicos pode ocultar (e, no limite, proteger) as injustiças internas aos grupos. $\mathrm{O}$ foco da autora está na relação entre as tradições, o papel de homens e mulheres para sua reprodução e as formas de dominação - e patriarcalismo - que encerram. Também aqui, a dualidade entre o público e o privado é central. É na rotina doméstica, no espaço privado, que a correlação entre tradição e dominação feminina apresentar-se-ia de forma mais forte, limitando as possibilidades de autonomia, sobretudo, das mulheres.

É por ser um dispositivo central da reprodução dessa dicotomia que, em sua estrutura de gênero convencional, a família acentua as descontinuidades entre as esferas (organizando a intimidade, na esfera privada, em torno de valores para os quais é central a domesticidade feminina e definindo as relações na esfera pública como a interação entre indivíduos igualmente livres) e as continuidades entre elas (diferenciando os papéis de homens e mulheres em cada uma dessas esferas, tornando complementares a participação dos homens na esfera pública e a determinação dos encargos das mulheres na esfera privada, sobretudo em sua responsabilidade pela criação dos filhos). Para Okin, não existe um problema na família como instituição. O problema estaria na estrutura de gênero da família, que restringe as oportunidades das mulheres, em especial, e torna mulheres e crianças vulneráveis. A dualidade entre o público e o privado equivale, neste ponto, ao problema da divisão sexual do trabalho. 
A divisão sexual do trabalho doméstico impõe às mulheres ônus que serão, então, percebidos como deficiências em outras esferas da vida (OKIN, 1989a, p. 133). A conexão entre os aspectos doméstico e não-doméstico da vida é profunda e permeia todos os espaços e atividades (idem, p. 126). As formas de definir - e restringir - o papel da mulher em uma dessas esferas organizam suas possibilidades de vida nas outras. Assim, a responsabilidade exclusiva pela gestão da vida doméstica corresponde, ao mesmo tempo, à vulnerabilidade na vida privada (em que os arranjos convencionais ou quase-convencionais ${ }^{7}$ produzem desvantagens para as mulheres, que têm menos tempo e recursos para qualificar-se e investir em sua vida profissional, permanecendo dependentes ou obtendo rendimentos menores do que os dos homens) e na vida pública (em que as habilidades e afetos desenvolvidos pelo desempenho dos papéis domésticos serão desvalorizados e, em alguns casos, vistos como indesejáveis para uma atuação profissional satisfatória).

A discussão sobre a vulnerabilidade das mulheres no casamento é um exemplo importante de como Okin percebe a interconexão entre as esferas e as especificidades nos arranjos familiares. Pode-se pensar em vulnerabilidade e dependência mútua no casamento, com formas variáveis de assimetria (inclusive no amor de um dos parceiros pelo outro) que não coincidem com as diferenças entre os sexos. Mas há, no casamento, ao lado dessas especificidades, padrões de gênero socialmente estruturados que envolvem as mulheres no que a autora define como "ciclos de vulnerabilidade socialmente causada e distintamente assimétrica" (idem, p. 138). Nas sociedades contemporâneas, a vulnerabilidade das mulheres é, em grande medida, produzida pelo casamento: "Elas são primeiramente expostas à vulnerabilidade durante o período de desenvolvimento por suas expectativas pessoais (e socialmente reforçadas) de que serão as principais responsáveis pelo cuidado com as crianças, e que para preencher esse

\footnotetext{
7 Entende-se por arranjos quase-convencionais aqueles em que as mulheres têm uma atuação na esfera pública, do trabalho, que lhe confere valorização e renda, mas fica mantida, na esfera doméstica, a divisão convencional dos encargos e expectativas. São, assim, os arranjos relacionados à noção de dupla jornada e ao problema da divisão desigual do tempo, com impacto sobre a participação política das mulheres e o lazer, entre outros aspectos.
}

papel elas precisarão atrair e manter o suporte econômico de um homem, para cuja vida profissional se espera que elas dêem prioridade. Elas se tornam vulneráveis pela divisão atual do trabalho dentro de quase todos os casamentos atuais. Elas têm desvantagens no trabalho pelo fato de que o mundo do trabalho pago, incluído o profissionalizado, é ainda amplamente estruturado em torno da presunção de que "trabalhadores" têm esposas em casa. Elas se tornam ainda mais vulneráveis se são as principais responsáveis pelo cuidado com as crianças, e sua vulnerabilidade atinge um pico se seus casamentos terminam e elas se tornam mães solteiras" (idem, p. 139).

De um lado, o foco na domesticidade e nos filhos não corresponde à valorização em outras esferas da vida. De outro, a posição do homem como provedor, inserida em um contexto de valorização social do sucesso econômico (que tende a ser ainda mais destacado quando é acompanhado de uma identidade profissional socialmente valorizada), reforça seu domínio e as possibilidades de exercer constrangimento na esfera doméstica. Em outras palavras, o dinheiro "do marido" desdobra-se em formas de valorização e de exercício de poder nas esferas não-doméstica e doméstica, enquanto o exercício continuado do cuidado com a família e do suporte à vida profissional do marido desdobra-se em restrições a uma atuação exitosa da mulher em outras esferas, reforçando o pré-conceito, combatido pelo feminismo, de que existem talentos e tendências naturalmente diferenciadas entre os sexos. Pode-se pensar que, nas sociedades contemporâneas, o problema está menos na exclusão ou veto à participação da mulher em esferas de exercício profissional e atuação política, e mais nas formas assumidas por essa participação. O silenciamento de suas perspectivas e a imposição de uma atuação "masculina", brevemente mencionadas por Okin (idem, p. 133), expõem os ruídos entre trajetórias e linguagens marcadas pelas experiências e valores que organizam a vida doméstica e as normas e valores que distinguem os indivíduos em sua atuação em outras esferas. As expectativas convencionais sobre o papel da mulher, especialmente aquelas que definem seu valor a partir da capacidade de cuidar dos outros e de renunciar a seus interesses, podem permanecer mesmo em meio a transformações na atuação e auto-percepção das mulheres, assim como na multiplicação dos tipos de arranjo nos casamentos. 
Por todas essas razões, a vida doméstica precisa ser justa: é impossível dissociar as esferas privada e pública. Além disso, a vulnerabilidade das mulheres (e das crianças) é produzida pelos desdobramentos dos arranjos na vida privada para as chances de auto-determinação em outras esferas da vida. Nas palavras de Susan Okin: "uma esfera importante de divisão de muitos bens sociais, dos materiais aos intangíveis, a distribuição desses bens no âmbito da família, tem sido, historicamente, muito longe de justa" (idem, p. 135). A superação da estrutura de gênero e das formas de subordinação das mulheres que ela encerra depende da confrontação com as injustiças na familia - apresentadas sob a forma da relação entre os papéis domésticos e as formas de segregação no mundo do trabalho e da relação entre a socialização em famílias com estrutura de gênero e os aspectos psicológicos da opressão (idem, p. 125).

A visão de que a família é uma esfera crucial para o desenvolvimento moral e, portanto, para o desenvolvimento do senso de justiça poderia significar o reconhecimento da centralidade das relações de gênero. Em John Rawls, como em outros teóricos da justiça analisados por Okin e mencionados antes neste artigo, essa compreensão não é incorporada devido à marginalidade das relações intra-familiares nesse debate. No Rawls de Uma teoria da Justiça ${ }^{8}$, para o qual se dirigem as críticas e adesões de Okin, a família aparece relacionada a três tópicos: a justiça inter-geracional (com a preocupação voltada para o princípio da poupança), a família como obstáculo para a justiça (com a preocupação voltada para as desigualdades entre as famílias e, portanto, para as vantagens e desvantagens nos valores e estímulos internalizados pelas crianças) e a família como escola de ensinamentos morais (com a preocupação voltada para a reprodução do senso de justiça).

\footnotetext{
8 Justice, Gender and the Family foi publicado em 1989 quatro anos antes, portanto, da primeira publicação de Political Liberalism, em 1993. A crítica de Okin não inclui este último e é esta a principal razão pela qual este artigo não incorpora conceitos-chave do Rawls de 1993, como o de "consenso sobreposto". Além desta razão, há outra. Political Liberalism mantém, em larga medida, o silêncio sobre a justiça na família. Justiça como eqüidade, publicação de 2002, organizada a partir de palestras proferidas em Harvard ao longo da década de 1980, é aqui considerada por uma razão, em especial: ali estão as "respostas" de Rawls às críticas feitas por Okin.
}

É esta última que de fato interessa a Okin. O argumento de Rawls, tomado pela autora em sua discussão, relaciona a estabilidade em uma sociedade bem ordenada - esquematicamente, aquela em que há consenso quanto aos princípios de justiça - à permanência do sentido de justiça entre seus membros ${ }^{9}$. A "família monogâmica" está entre as principais instituições da estrutura básica da sociedade (RAWLS, 2008, p. 8). Pressuposta sua justiça, teria, assim, um papel fundamental no desenvolvimento moral dos cidadãos. Mas essa moralidade se relaciona centralmente ao exercício da autoridade dos pais (sem a especificação do sexo) sobre os filhos. $\mathrm{O}$ amor dos pais pelos filhos desperta neles a noção de seu próprio valor. Além disso, a enunciação de regras claras, inteligíveis e justificáveis e a exposição dos motivos para que essas regras sejam seguidas em comum por pais e filhos promovem o desenvolvimento moral das crianças: "os pais devem dar o exemplo da moralidade que exigem" (idem, p. 575). A criança, segundo Rawls, "adquire a disposição de acatar essas proibições porque as vê dirigidas a ela por pessoas poderosas, que têm seu amor e confiança, e que também agem em conformidade com elas" (ibidem). Nesse sentido, as referências para o comportamento virtuoso são dadas pelas expectativas dos pais, o que se estenderia aos "ideais adotados mais tarde na vida e, assim, às diversas condições e ocupações de um adulto, à posição na família e até à posição da pessoa na qualidade de membro da sociedade" (idem, p. 577). Não há, no entanto - e é este o ponto central à crítica de Okin -, nenhuma menção às relações de gênero na família. $\mathrm{O}$ último trecho citado, que fala da extensão dos ideais morais presentes na socialização primária à vida adulta, apenas menciona que "o conteúdo desses ideais provém das diversas concepções de boa esposa e bom marido, bom amigo e bom cidadão" (ibidem).

\footnotetext{
9 A sociedade bem ordenada é aquela na qual "todos aceitam e sabem que os outros aceitam os mesmos princípios de justiça, e as instituições sociais básicas atendem e se sabe que atendem a esses princípios" (RAWLS, 2008, p. 560). Ela resiste ao tempo porque quando as instituições são justas, "os que participam desses arranjos institucionais adquirem o correspondente senso de justiça e desejam fazer sua parte para preservá-la" (idem, p. 561). É importante, também, o fato de que na sociedade bem ordenada os padrões de justiça universalmente reconhecidos convivem com distintas concepções de bem e juízos de valor (a distinção entre o justo e o bem é exposta, especialmente, entre as páginas 552 e 558 de Uma teoria da Justiça).
} 
A família apareceria novamente na parte final de Uma teoria da Justiça, na discussão sobre união social. Para esta análise, interessa apenas que a família e as relações entre os sexos estejam entre as formas de união social. Enquanto a família é definida como união social sem reservas ou especificações, juntamente com a amizade, a relação entre os sexos só pode ser uma união social se a ela "se fundirem elementos de afeto e amizade", ultrapassando sua feição instrumental. Para Okin, a presunção da justiça $d a$ família e o silêncio a respeito de como se estabelecem as relações $n a$ família estabelecem uma tensão na teoria de Rawls, que só se resolveria pelo enfrentamento aberto do problema da justiça intrafamiliar: "Ao menos que os ambientes domésticos nos quais as crianças são primeiramente criadas, e vêm seus primeiros exemplos de interação humana, sejam baseados na igualdade e na reciprocidade em vez de na dependência e na dominação - e este último é, muito frequentemente, o caso - como o amor que elas recebem dos seus pais pode compensar a injustiça que elas vêm no relacionamento entre esses mesmos pais? [...]. Se os pais não dividem as atividades de criação, serão capazes de manter na idade adulta a capacidade de empatia que caracteriza o senso de justiça?" (OKIN, 1989a, p. 100).

A visão da família como escola primária de justiça, considerando o problema da desigualdade entre os sexos, está presente também em autoras como Nancy Chodorow (1999) e Carol Gilligan (1982). Em Justiça como eqüidade, em que, como se disse antes, Rawls dirige-se diretamente às críticas de Okin, fica mantida a compreensão de que a família é central para "garantir a produção e reprodução ordenadas da sociedade", mas o autor recua em sua definição da família como "monogâmica". Aqui a sociedade justa não exige uma forma particular de família, desde que seu arranjo permita "providenciar de maneira razoável e eficaz a criação e o cuidado dos filhos, garantindo seu desenvolvimento moral" e produzindo cidadãos com senso de justiça capaz de sustentar instituições políticas e sociais justas. É também função da família, para o autor, gerar "filhos em número adequado para a manutenção de uma sociedade durável" (RAWLS, 2003, p. 230-231) ${ }^{10}$. No mesmo livro, a preocupação com a divisão

10 Em nota (RAWLS, 2003, p. 231, 42), Rawls explica que os direitos e deveres de gays e lésbicas serão admissíveis, do ponto de vista da justiça como equidade, se forem "co- sexual do trabalho é explicitada. Essa "injustiça longa e histórica para com as mulheres" pesaria sobre elas e minaria a capacidade de aquisição das virtudes políticas pelas crianças (idem, p. 15, 235). Rawls chega mesmo a afirmar que quando os encargos domésticos são desiguais, as mulheres teriam direito a parcela igual da renda obtida pelo marido durante o período de duração do casamento.

Essas mudanças não impedem que o autor mantenha a compreensão de que os princípios da justiça política aplicam-se à estrutura básica da sociedade, de que faz parte a família, mas não se aplicam diretamente a sua "vida interna". A família é, assim, comparada às igrejas e às universidades e, nesse sentido, "nada tem de peculiar" (idem, p. 232). As restrições garantiriam que a família se organizasse de acordo com os dois princípios básicos da justiça em Rawls - liberdades básicas e oportunidades equitativas para todos os cidadãos. Mas a posição dos indivíduos como cidadãos, à qual se aplicam os princípios da justiça que garantiriam a igualdade e independência iguais para homens e mulheres, deve ser distinta de "seu ponto de vista como membros de famílias e de outras associações". Essa distinção é que permitiria uma "vida interna livre e fecunda" para as associações, entre elas a família (idem, p. 233-4) ${ }^{11}$.

Okin discorda de Rawls, sem abrir mão de pressupostos centrais a sua teoria. Advoga, simultaneamente, pelo enfrentamento dos problemas relacionados à justiça intra-familiar e pela

erentes com a vida familiar ordenada e a educação das crianças". Isso mostra como a recusa formal à adesão a valores morais específicos não impede - e, pelo contrário, mantém ocultos - entendimentos e visões de mundo que determinam julgamentos.

11 Neste ponto, Rawls retoma a discussão presente em Teoria da Justiça sobre a moralidade na relação entre pais e filhos. Novamente, a família deve ser presumida justa mas o foco é, então, retirado das relações de gênero. A afirmação de que "a sociedade tem de confiar na afeição e na boa vontade natural dos pais" é seguida por uma nota (n. 48, p. 234), em que explica que a justiça como equidade não se propõe a "restaurar o caráter moral da família" e que as concepções de justiça que se considera apropriadas não são suficientes para tanto. Essa explicação rebate o que teria sido um entendimento errôneo de Michael Sandel em Liberalism and the Limits of Justice. No sentido oposto ao dos argumentos de Okin, Sandel critica Rawls por impor princípios de justiça ("integridade e judiciosidade inquestionáveis") a uma esfera que seria regida por afeto e franqueza. 
potencialidade da teoria rawlsiana da justiça para sua realização. Pode-se sustentar que está aí a principal especificidade desse diálogo. A próxima seção analisa a crítica de Okin à distinção entre "ética do cuidado" e "ética da justiça" e sua defesa de que a abordagem de Rawls, em seu recurso à noção de "posição original", permite colocar o cuidado e a empatia no centro da teoria da justiça, ao mesmo tempo em que preserva a imparcialidade como valor.

\section{EMPATIA, IMPARCIALIDADE E JUSTIÇA}

O núcleo de Uma teoria da Justiça permanece influente e polêmico mesmo depois da publicação de $O$ liberalismo político, que apresenta uma série de modificações e reconsiderações a partir das críticas ao primeiro, com uma maior ênfase ao pluralismo político e cultural. Há dois aspectos centrais a esse núcleo teórico original. O primeiro consiste na definição dos dois princípios básicos da justiça como equidade, que são a garantia de liberdades básicas e oportunidades equitativas.

Em sua obra posterior, esses dois princípios continuariam a ser centrais, com uma ênfase ampliada na análise do "princípio de diferença" e de seus desdobramentos para a justiça. Esse princípio é fundamental para a noção de equidade em Rawls. É por meio dele que se define que as desigualdades só se justificam quando forem vantajosas para aqueles que estão em posição menos favorável. O princípio da diferença parte do pressuposto de que ninguém "merece" um ponto de partida favorável, mas as diferenças não podem ser simplesmente ignoradas (RAWLS, 2008, p. 121$2)^{12}$. Fazem parte do princípio da diferença, sem que coincidam completamente, os princípios de reparação, de reciprocidade e de fraternidade. Um exemplo deste último seria, justamente, a família, em uma concepção idealizada que se realizaria "quase sempre na prática". Nela, os indivíduos

\footnotetext{
12 Nesse ponto, Rawls refere-se à família em um argumento que confronta diretamente a lógica meritocrática e explicita uma das concepções de família presentes em sua obra, a de que a família pode ser um empecilho à igualdade de oportunidades: "é problemática a situação de saber se merecemos o caráter superior que nos possibilita fazer o esforço de cultivar nossas capacidades, pois esse caráter depende, em grande parte, de circunstâncias familiares e sociais afortunadas no início da vida, pelas quais não temos nenhum crédito" (RAWLS, 2008, p. 124).
}

recusar-se-iam a ganhar, "a não ser que possam fazê-lo de modo a promover os interesses dos demais" (idem, p. 126). Nesse, como em outros momentos, Rawls sustenta uma concepção idealizada da família, destacando o altruísmo e silenciando sobre a ausência de reciprocidade nas relações familiares.

O segundo aspecto desse núcleo teórico inicial, aquele que mais interessa a este artigo, está presente nos conceitos de "posição original" e "véu da ignorância". A partir das críticas a Uma teoria da Justiça, as discussões presentes em O liberalismo político representariam um recuo nos argumentos de Rawls fundados nesses conceitos, sem que, no entanto, as noções de imparcialidade e neutralidade deixassem de ser valores centrais à teoria da justiça. Em conjunto com os dois princípios da justiça, a "posição original" faz parte da defesa da "equanimidade decorrente da ignorância” (KOLM, 2000, p. 211). É, provavelmente, sua formulação de maior impacto, mas também a fonte dos principais problemas de sua teoria quando se considera que existe uma correspondência entre a defesa da imparcialidade presente na posição original e a naturalização de valores e perspectivas hegemônicas, ocultos sob a suspensão dos interesses e das especificidades (YOUNG, 1990).

A oposição entre auto-interesse e senso público de justiça precede a defesa da justiça social como "equilíbrio apropriado entre exigências conflitantes" (RAWLS, 2008, p. 12). A ausência de acordo equivale ao egoísmo generalizado (idem, p. 165), enquanto a posição original configura, na situação contratual, um "procedimento equitativo" do qual derivam os princípios justos. É indispensável que esse procedimento anule as contingências específicas "que geram discórdia entre os homens". O "véu da ignorância" é, assim, o dispositivo que permite que os indivíduos estejam em uma situação de igualdade hipotética, que neutraliza "os acidentes da dotação natural e das contingências de circunstâncias sociais como fichas na disputa por vantagens políticas e econômicas" (idem, p. 18), anulando as arbitrariedades. A ignorância sobre sua própria posição e sobre as vantagens e desvantagens a ela relacionadas teria duas funções centrais: restringir os argumentos, que não podem então ser fundados em interesses, laços afetivos e inclinações individuais; levar os indivíduos a assumir o "ponto de vista de qualquer 
pessoa selecionada ao acaso": "como as diferenças entre as partes lhes são desconhecidas, e todos são igualmente racionais e estão situados de forma similar, cada qual é convencido pelos mesmos argumentos" (idem, p. 169). A falta de informações sobre o que singulariza os indivíduos - e o fato de que as informações relevantes sejam sempre as mesmas - é o que garante que os princípios escolhidos serão sempre os mesmos. Isso impediria simultaneamente a busca pelo auto-interesse e a interferência de preconceitos, como os de raça e sexo. Como desconhecem as consequências que os princípios acordados podem ter sobre sua própria situação, indivíduos morais e racionais escolherão princípios cujas consequências estejam dispostos a aceitar, sejam quais forem suas situação e posição.

$\mathrm{Na}$ posição original, os indivíduos conhecem, assim, apenas "fatos genéricos acerca da sociedade humana", leis e teorias gerais (políticas, econômicas e psicológicas) que possam garantir uma cooperação social estável. No entanto, "ninguém sabe qual é seu lugar na sociedade, classe nem status social; além disso, ninguém conhece a própria sorte na distribuição dos dotes e das capacidades naturais, sua inteligência e força, e assim por diante. Ninguém conhece também a própria concepção de bem, as particularidades de seu projeto racional de vida, nem mesmo as características especiais de sua psicologia, como sua aversão ao risco ou sua tendência ao otimismo ou ao pessimismo. Além do mais, presumo que as partes não conhecem as circunstâncias de sua própria sociedade. Isto é, não conhecem a posição econômica ou política, nem o nível de civilização e cultura que essa sociedade conseguiu alcançar. As pessoas na posição original não sabem a qual geração pertencem" (ibidem).

Quando discute a justiça intergeracional, já mencionada antes neste artigo, Rawls convida o leitor a "supor que as partes são chefes de família ${ }^{13}$ e que têm, em virtude disso, o desejo de promover o bem-estar de pelo menos seus descendentes imediatos" (idem, p. 156). Ao mesmo tempo, pressupõe que as partes, na posição original, não têm laços fortes de sentimentos e são mutuamente desinteressadas. A ausência de informações sobre si e sobre os demais cria uma cir-

\footnotetext{
13 No original, "heads of families".
}

cunstância em que cada indivíduo vê restrita sua possibilidade de defender os próprios interesses ou de sacrificar seus interesses em benefício dos outros (idem, p. 157).

A posição de Susan Okin, como se disse antes, acomoda-se em larga medida aos pressupostos da teoria da justiça em Rawls. Isso se dá, sobretudo, porque ela concorda com a conexão feita por Rawls entre a abstração das particularidades dos indivíduos na posição original, gerando uma posição simétrica que, então, formalizaria a "convicção refletida de que, em matéria de justiça política básica, os cidadãos são iguais em todos os aspectos relevantes" (RAWLS, 2003, p. 25). Para a autora, o problema na abordagem de Rawls está no fato de que ignora a estrutura de gênero e as injustiças na família. A suposição de que os indivíduos na posição original sejam "chefes de família”, para Okin, não é reveladora de problemas estruturantes no recurso à "posição original". Pelo contrário, a autora entende que esta suposição contradiz outra, que deve ser preservada: a de que nessa circunstância contratual os indivíduos ignoram seu sexo e outras características individuais. Descartado o problema de que os indivíduos são caracterizados como "chefes de família", Okin entende que os princípios de justiça de Rawls são capazes de expressar e potencialmente garantir a igualdade entre os indivíduos. Aplicados à estrutura de gênero e à família, potencializariam transformações importantes (OKIN, 1989b, p. 235).

Nessa argumentação, a consideração das especificidades produziria critérios orientados pelo auto-interesse e pelos conflitos entre as diferentes inclinações dos indivíduos. Suspensas essas especificidades, seria possível atingir hipoteticamente princípios universais, destituídos das arbitrariedades derivadas da consideração da posição de indivíduos específicos. Esses princípios seriam, então, definidos a partir da posição de qualquer um, isto é, dos interesses que serviriam a cada um de nós, homens ou mulheres, brancos ou negros, adultos ou crianças, heterossexuais ou homossexuais, amantes de Mozart ou das músicas mais tocadas na rádio local de maior sucesso. Assim, ao mesmo tempo em que Okin sustenta que a desconsideração das perspectivas das mulheres e das crianças leva a uma análise que silencia sobre a justiça na família (porque leva a enxergar a família a partir da posição dos "chefes de 
família"), vê a suspensão do sexo dos indivíduos na posição original como recurso epistemologicamente adequado, que se desdobra em garantias políticas e, potencialmente, na igualdade entre os sexos.

A defesa que Susan Okin faz do artifício da "posição original" inclui, centralmente, o entendimento de que a suspensão das especificidades permite a empatia e a abertura para os pontos de vista dos outros (OKIN, 1989a, p. 101). A "posição original" seria palatável à crítica feminista porque não existe um vínculo necessário entre a imparcialidade que esse recurso permitiria e a racionalidade como base para a ação. Ainda que a linguagem da escolha racional, como caracterizada pela autora, e as noções kantianas de razão e autonomia estejam presentes em Rawls, a racionalidade não seria, para esse autor, suficiente para sustentar a teoria da justiça. A ausência dos próprios interesses equivaleria, nos argumentos assumidos por Okin, à consideração da posição social dos outros indivíduos, fundada na empatia. Pode-se assumir, com a autora, que a suspensão dos interesses, exigida pela posição original, exclui comportamentos estratégicos orientados para sua consecução. O único interesse seria, portanto, o de minimizar os riscos de encontrar-se em desvantagem, uma vez estabelecidos os critérios de justiça - já que não conheço minha posição social e minhas características individuais. O problema na crítica de Okin é que ela desconsidera que, suspensas as especificidades, os atores na posição original são réplicas de um mesmo indivíduo abstrato, dotado de racionalidade e autonomia, mas despido das características que o identificariam socialmente.

O princípio da diferença e a posição original imporiam, segundo Okin, a empatia e a consideração das diferenças, mesmo que a linguagem racionalista kantiana de Rawls não lhe permita assumir ou dar-se conta disso. Nesse aspecto, a crítica de Okin é bastante peculiar. Ela ressalta o que estaria potencialmente presente na obra de Rawls, mesmo que o autor não tenha escolhido desenvolvê-la nesse sentido. Por isso, vê como incongruências as tensões entre a negligência da justiça na família e a consideração das famílias justas como base para a estabilidade da sociedade bem ordenada, de um lado, e entre a linguagem racionalista e o entendimento, que atribui a Rawls, de que o desenvolvimento do senso de justiça de- pende de laços e sentimentos, de outro (OKIN, 1989b, p. 238). Apoiando-se em afirmações de Rawls sobre a continuidade entre senso de justiça e humanidade (RAWLS, 2008, p. 603) e, sobretudo, no entendimento de que o desenvolvimento moral depende do amor, da confiança e da afeição, Okin coloca a empatia no centro da teoria da justiça. Os fatos de que o "amor à humanidade"14 tenha sido, historicamente, um ideal ao mesmo tempo abrangente e excludente e de que a afeição mencionada por Rawls ao discutir os estágios do desenvolvimento moral esteja atada a uma concepção evidentemente romantizada da família, são silenciados (no primeiro caso) ou entendidos como problemas que podem ser neutralizados (no segundo). Como não percebe essas tensões como reveladoras de problemas estruturais nas concepções assumidas por Rawls, a "posição original" continua a ser, apesar delas, defendida como um ponto de vista moral adequado: "Rawls não se considera como alguém que segue esse caminho, acreditando que ele levaria ao utilitarismo clássico e não aos dois princípios de justiça. Mas, segundo defendo, porque ele reduz o conhecimento daqueles que participam da posição original ao ponto de não poderem empregar a razão probabilística e não poderem ser vistos como assumindo riscos, Rawls tem que sustentar sua posição na empatia, na benevolência e na preocupação igualmente com os outros e consigo mesmo, para que os pares cheguem aos princípios que escolhem, especialmente o princípio da diferença" (OKIN, 1989b, p. 243).

A leitura que faz de Rawls serviria, assim, para sustentar sua crítica à dicotomia entre "ética do cuidado" e "ética da justiça". A combinação entre imparcialidade e benevolência forçaria as pessoas, na posição original, a levar em conta o bem dos outros, a colocar-se na posição de todos os outros. A necessidade de levar em conta o ponto de vista dos menos favorecidos demandaria a capacidade de ouvir os outros, levá-los em consideração. Mas isso não restringiria os princípios de justiça daí provenientes ao âmbito do cuidado ou da ética relacional, no sentido definido por Carol Gilligan e Nel Nodding, mencionadas por Okin, em sua caracterização de uma ética fundada no "feminino". De um lado, não haveria, inclusive

\footnotetext{
14 No original, "love of mankind".
} 
nas entrevistas em que se baseia o trabalho de Gilligan, evidências suficientes de que a moralidade das mulheres tende a ser mais particularista e contextual. De outro, ao valorizar os sentimentos, o cuidado e a preocupação com o outro, vendo-os como essenciais à formulação de princípios de justiça, Okin não está advogando pela substituição desses princípios pelo pensamento contextual, fundado no cuidado. O problema não estaria nos princípios ou regras per se, mas em como se chega a eles. Se os princípios de justiça não forem fundados no desinteresse mútuo e no afastamento em relação aos outros, "mas na empatia e no cuidado com os outros", com atenção às diferenças, "dificilmente levarão a regras destrutivas, que tenham consequências trágicas quando aplicadas àqueles que amamos" (idem, $\mathrm{p}$. 247). Os princípios de justiça em Rawls seriam desse último tipo.

Assumindo outro rumo, e deixando de lado o esforço de Okin para situá-la diferentemente de como foi apresentada pelo próprio Rawls, a teoria da justiça exige que a perspectiva assumida coincida com a posição de "cidadania igual e dos diversos níveis de renda e riqueza" (RAWLS, 2008, p. 118). Como exceção, Rawls considera situações em que outras posições deveriam ser levadas em conta. Curiosamente, as "características naturais físicas" que implicam em desigualdades, entre as quais as diferenças entre os sexos, constituem posições relevantes quando fundamentam direitos básicos desiguais. Essa desigualdade só se justifica, então, de acordo com o "princípio de diferença", se for "vantajosa para as mulheres e aceitável do ponto de vista delas" (ibidem). O autor deixa claro, no entanto, que as desigualdades multiplicam as posições, complicam a aplicação dos dois princípios da justiça e raramente trazem vantagens para os menos favorecidos. Deve-se, portanto, trabalhar com o menor número possível de posições relevantes, isto é, com posições que correspondam a um "ponto de vista geral", levando em conta "os interesses de todos, pois todos são cidadãos iguais e têm seu lugar na distribuição de renda e riqueza ou no âmbito das características naturais fixas em que se baseiam as distinções" (idem, p. 119). Pode-se, em um esforço interpretativo oposto ao de Okin - e que exige bem menos de quem o impetra - assumir, com Serge-Cristophe Kolm (2000, p. 235), que "os indivíduos na posição original são todos idênticos".
IV. CONSIDERAÇÕES FINAIS: AADESÃOAOS VALORES LIBERAIS E A (DES)CONSIDERAÇÃO DAS PERSPECTIVAS DAS MULHERES

O que fica de fora da análise de Susan Okin é o problema da dominação. Pode parecer um contrassenso dizer isso de uma autora que apresenta preocupações e análises fundamentais sobre as desigualdades de gênero na família e as relações de opressão em comunidades e tradições culturalmente identificadas. Mas ao assumir que o artifício da "posição original" é adequado porque permite, às partes, pensar a partir da posição de qualquer outro indivíduo, Okin rejeita algo que está presente, mesmo que marginalmente, na obra do próprio Rawls: a disputa e os conflitos quanto a posições, bens (tangíveis e intangíveis) e visões de mundo. A idéia de que, se os indivíduos fossem iguais, seriam estes os princípios de justiça acordados esbarra em um problema efetivo, que consiste no fato de que eles não ocupam posições iguais nos contextos sociais concretos aos quais ambos referem-se, as sociedades liberais contemporâneas. E por mais que a "posição original" seja uma abstração, a suspensão das especificidades e das hierarquias pode servir, justamente, para ocultar aspectos centrais - e concretos - das desigualdades que se pretende superar.

A pergunta que levaria os indivíduos à reflexão e, potencialmente, à empatia, na teoria da justiça em John Rawls - "o que é o bem para cada um e para todos os seres humanos cuja sociedade será governada por esses princípios?" (OKIN, 1989b, p. 72) - não pode, de fato, ser feita a partir de um lugar isento das inflexões que as trajetórias, interesses e visões de mundo imprimem ao olhar que lançamos à nossa própria posição, como indivíduos, e à dos demais. O problema não é, portanto, o caráter ficcional da "posição original". É, diferentemente, saber se é desejável que essa ficção oriente, normativamente, o debate sobre justiça e se ela permite uma compreensão das relações sociais e de poder adequada para a produção de uma sociedade mais justa e, dentro do nosso enfoque, menos opressiva para as mulheres. Em sua crítica aos comunitaristas, Susan Okin afirma que as teorias da justiça que dependem das tradições e dos significados compartilhados não são capazes de lidar adequadamente com o problema da dominação. Isso se daria, especialmente, por serem fundadas em alguns pontos de vis- 
ta, mais do que em outros (idem, p. 69). Essa preocupação da autora poderia ser estendida à discussão sobre a teoria da justiça em Rawls. Levando em conta as formas de dominação e opressão que constituem as hierarquias em contextos concretos, é possível sustentar que os pontos de visa de cada um e de todos não estão em condições iguais para se fazer ver e se fazer valer e, em especial, para que sejam compreendidos como representativos de posições socialmente relevantes.

Nas palavras de Iris Marion Young (1990, p. 4), "se a teoria é verdadeiramente universal e independente, não pressupondo quaisquer situações sociais, instituições ou práticas particulares, então ela é simplesmente abstrata demais para ser útil para a avaliação das instituições e práticas existentes". Para que seja útil para avaliar os graus de justiça e injustiça, "deve conter premissas substantivas sobre a vida social, que normalmente derivam, explícita ou implicitamente, do contexto social atual em que a teorização se situa". Assim como a teoria da justiça proposta por John Rawls é, ela mesma, situada social e historicamente, as posições representativas que tomam parte da situação original do contrato não são puras abstrações. O fato de que as partes na "posição original" sejam "chefes de família", em Teoria da Justiça, não é um equívoco que nega uma moldura teórica que, de outro modo, seria verdadeiramente capaz de colocar-se de um ponto de vista universal. Revela, diferentemente, que este, assim como outros aspectos das relações de poder efetivas, constitui premissas para a ordem social descrita e desejada, mesmo quando elas não são claramente enunciadas. Ainda que não seja possível desenvolver essa discussão adequadamente dentro dos limites deste artigo, é preciso destacar que os conflitos quanto às posições capazes de se fazer ver e se fazer valer não existem apenas quando as hierarquias são visíveis e os argumentos para a manutenção de alguns indivíduos em condição de subordinação são explicitados, como no recurso às tradições culturais e religiosas, discutido por Okin na crítica aos comunitaristas e multiculturalistas. A universalidade, a imparcialidade e a neutralidade contêm posições que podem não ser reconhecidas enquanto tal justamente porque elas são o desdobramento de valores e normas hegemônicas. A naturalização da dominação, materializada em estruturas sociais específicas, permite apresentar como neutros os valores que a sustentam.
Neste ponto, o problema da dominação pode ser abordado sob dois aspectos: as bases históricas liberais do feminismo e a consideração das perspectivas "femininas". Pode-se assumir que o liberalismo engendrou, historicamente, $\mathrm{o}$ feminismo tal como o conhecemos. Esta afirmação, em sua generalidade, não pretende oferecer respostas para a complexidade da estrutura de gênero nas sociedades contemporâneas ou congelar, nesta herança, um conjunto variado de empreitadas teóricas realizadas em diferentes momentos. Indica, apenas, que a noção liberal de indivíduo e a conexão entre os valores liberais da igualdade, da liberdade e da universalidade são um marco relevante a partir do qual se estabeleceram críticas e lutas, entre elas as das mulheres. Historicamente, a afirmação de que todos são iguais e que as normas sociais vigentes devem ser um desdobramento dessa igualdade permitiu, ao mesmo tempo, as lutas em busca de sua realização $e$ a ocultação de formas efetivas de opressão e marginalização que permanecem acomodadas a princípios normativos universais. A obra de Rawls pode ser vista como uma resposta a essa situação, no contexto do Welfare State norte-americano e europeu - o princípio da diferença procura estabelecer a equidade de oportunidades e parte, justamente, do reconhecimento de que, deixados à própria sorte, os indivíduos padeceriam das vantagens e desvantagens que sua posição social, familiar e características "naturais" os impõem. Em outras respostas, no entanto, ressalta-se justamente que a tensão entre a igualdade formal e os privilégios sistemáticos é estruturante das sociedades capitalistas liberais. Para confrontá-la, seria preciso expor os limites do próprio liberalismo e o fato de que as relações de trabalho e as relações familiares, para citar apenas dois exemplos, são núcleos de reprodução das desvantagens de grupos sociais específicos, como as mulheres. Ao contrário da expectativa de Okin de que a pressuposição da igualdade (o se todos fossem iguais) é adequada para a produção de uma sociedade que supere o gênero, parece mais adequada a compreensão de que tratar as pessoas "simplesmente como pessoas" pode colaborar para a reprodução e naturalização das desigualdades, entre elas as de gênero. A democracia teria, assim, que ser reconceitualizada com as diferenças sexuais em mente (PHILLIPS, 1991).

Isso nos leva ao segundo ponto, com o qual este artigo se encerra. Susan Okin levanta questões relevantes para a teoria política feminista quan- 
do defende que a oposição entre "ética do cuidado" e "ética da justiça" deve ser superada (OKIN, 1989b). Para ela, a suspensão dos vieses decorrentes dos afetos e das características de cada um não se opõe à empatia e ao cuidado. Imparcialidade, empatia e consideração das diferenças poderiam, assim, fazer parte de uma mesma formulação teórica. A adesão normativa aos valores liberais da imparcialidade e da universalidade impede, no entanto, como se disse acima, o tratamento adequado das formas efetivas de dominação. O lugar social a partir do qual se constituem visões legitimamente tomadas como "imparciais" pode determinar quem será objeto de empatia, quem será estigmatizado e quem será silenciado. Do mesmo modo, procedimentos supostamente imparciais podem silenciar sobre os critérios que definem quem será, de fato, levado em consideração, e por quais razões ${ }^{15}$. O ponto de vista universal e imparcial não é apenas impossível de ser atingido - por expressar, sempre, perspectivas situadas em relação a contextos e demandas sociais concretas -, é, também, indesejável porque dá suporte à idéia de Estado neutro, legitima a autoridade burocrática e as hierarquias nos processos decisórios e, o que contém as duas afirmativas anteriores, reforça a opressão ao apresentar o ponto de vista dos grupos privilegiados como universal (YOUNG, 1990) ${ }^{16}$

A crítica de Okin pode permitir, apesar dessas deficiências, a superação do contraponto ingênuo entre vozes "femininas" e "masculinas" nas análises sobre os contextos de interação e deliberação em que os critérios de justiça são produzidos. A crítica ao apagamento das perspectivas das mulheres não corresponde, neste artigo e na obra de Okin, à compreensão de que existem experiências femininas fundadas em uma ética alternativa (por serem femininas) e descoladas dos valores da dominação (por sua condição histórica de subordinação). Em suas análises da família, mas especialmente em sua crítica ao multiculturalismo,

15 Para uma análise do impacto da adesão ao valor da imparcialidade para a representação da pluralidade social nos meios de comunicação, ver Miguel e Biroli (2009).

16 Okin (1989b, p. 247) opõe-se explicitamente a esses argumentos, em uma breve menção ao artigo de Iris Marion Young que deu origem ao quarto capítulo do livro Justice and the Politics of DConseifference, intitulado "The ideal of imparciality and the civic public". a autora trata brevemente do problema da internalização de valores e da "internalização da subordinação" (OKIN, 1999, p. 128). Autores como Pierre Bourdieu (2007) e Catharine Mackinnon (1989), por caminhos bastante diversos, permitem desdobrar as preocupações presentes em Okin. Neles, o contraponto entre universalidade e especificidade (cultural, mas também de gênero) parece ser superado em abordagens que enfocam os mecanismos de constituição das identidades a partir de valores, gostos e distinções moldados pelas relações sociais de dominação. $\mathrm{Na}$ família, a estrutura de gênero, fundada na divisão sexual do trabalho, organiza a opressão, bloqueia as oportunidades das mulheres, e participa da produção dos afetos, das sensibilidades e de autoimagens que certamente não se reduzem à dualidade entre dominador e dominado.

De um lado, assim, a abstração das especificidades dos indivíduos não constitui, segundo a posição assumida neste artigo, um recurso adequado para a definição dos critérios que permitirão distinguir entre o justo e o injusto e superar as injustiças de gênero. Por outro lado, a consideração das diferentes perspectivas não está livre de problemas. O "resgate" da experiência feminina envolve a atenção às especificidades que se produziram nessas situações sociais concretas, em meio a relações de poder que constituem as identidades dos indivíduos, ainda que não as esgotem. O destaque dado por Susan Okin aos sentimentos e à empatia, levados ao centro da análise das interações que definirão critérios adequados de justiça, não constitui, assim, uma alternativa à artificialidade que advém da suspensão das relações de poder pelos dispositivos teóricos da justiça rawlsiana. Em outras palavras, a manutenção do recurso à "posição original" como ponto de vista moral adequado impede a consideração efetiva das especificidades porque neutraliza os conflitos presentes na interação entre os diferentes indivíduos, transformando seus interesses e perspectivas em posições empaticamente apreendidas por um sujeito universal. Além disso, enfraquece a crítica à visão idílica das relações familiares por acomodar-se a outra idealização: a de que é possível definir critérios para a superação das injustiças de gênero a partir de um ponto de vista universal e imparcial, que seria capaz de levar em conta, igualmente, os diferentes pontos de vista que se afirmam (ou são silenciados) em meio a relações assimétricas de poder. 
Flávia Biroli (fbiroli@terra.com.br) é Doutora em História pela Universidade Estadual de Campinas (Unicamp), Professora no Instituto de Ciência Política da Universidade de Brasília (UNB) e Pesquisadora do Conselho Nacional de Desenvolvimento Científico e Tecnológico (CNPq).

\section{REFERÊNCIAS BIBLIOGRÁFICAS}

BADINTER, E. 1985. O amor incerto: história do amor maternal (do séc. XVII ao séc. XX). Lisboa: Relógio D’Água.

BEAUVOIR, S. 2008. O segundo sexo. Lisboa: Bertrand.

BOURDIEU, P. 2007. A distinção: crítica social do julgamento. São Paulo: USP.

CHODOROW, N. 1999. The Reproduction of Mothering. Berkeley: University of California.

COHEN, J. 1997. Rethinking Privacy: Autonomy, Identity, and the Abortion Controversy. In: WEINTRAUB, J. \& KUMAR, K. (eds.). Public and Private in Thought and Practice. Chicago: University of Chicago.

ELSHTAIN, J. 1981. Public man, Private Woman. Princeton: Princeton University.

GILLIGAN, C. 1982. In a Different Voice: Psychological Theory and Women's Development. Cambridge, Mass.: Harvard University.

GINZBURG, N. 1988. Léxico familiar. Rio de Janeiro: Paz e Terra.

GOFFMAN, E. 2010. Relations in Public: Microstudies of the Public Order. London: Transaction.

KOLM, S.-C. 2000. Teorias modernas da Justiça. São Paulo: M. Fontes.

MACKINNON, C. 1989. Toward a Feminist Theory of the State. Cambridge, Mass.: Harvard University.

MIGUEL, L. F. \& BIROLI, F. 2009. A produção da imparcialidade: a construção do discurso universal a partir da perspectiva jornalística. XVIII Encontro Anual da Associação Nacional dos Programas de Pós-Graduação em Comunicação (COMPÓS), Belo Horizonte, 2 a 5 de junho.
MOI, T. 1999. What is a Woman? Oxford: Oxford University.

OKIN, S. 1979. Women in Western Political thought. Princeton: Princeton University.

. 1989a. Justice, Gender, and the Family.

New York: Basic Books.

1989b. Reason and Feeling in Thinking about Justice. Ethics, Chicago, v. 99, n. 2, p. 229-249.

1998. Gender, the Public and the Private. In: PHILlIPS, A. (org.). Feminism and Politics. Oxford: Oxford University.

. 1999. Is Multiculturalism Bad for Women? Princeton: Princeton University.

PATEMAN, C. 1989. Feminist Critiques of the Public/Private Dichotomy. In: . The Disorder of Women. Stanford: Stanford University.

1993. O contrato sexual. Rio de Janeiro: Paz e Terra.

PHILLIPS, A. 1991. Engendering Democracy. Cambridge: Polity.

RAWLS, J. 2000. O liberalismo politico. São Paulo: Ática.

. 2003. Justiça como eqüidade: uma reformulação. São Paulo: M. Fontes.

. 2008. Uma teoria da Justiça. São Paulo: M. Fontes.

RUDDICK, S. 1989. Maternal Thinking: Towards a Politics of Peace. Boston: Beacon.

YOUNG, I. M. 1990. Justice and the Politics of Difference. Princeton: Princeton University.

.2005. House and Home: Feminist Variations on a Theme. In: . On Female Body Experience. Oxford: Oxford University. 
GENDER AND FAMILY IN A JUST SOCIETY: ADHERENCE TO AND CRITIQUE OF IMPARTIALITY IN THE CONTEMPORARY DEBATE ON JUSTICE

\section{Flávia Biroli}

This article analyzes debates on justice and their implications for feminist critique. Our focus is on discussions of the need for an impartial point of view for producing criteria of justice, as they emerge from the works of John Rawls and Susan Okin. Okin's critique, as well as her adherence to Rawl's perspective, defends conciliating impartiality and feminist critique, in search of fairer gender relations. 
In Rawls, justice depends on the suspension of interests and affects linked to individuals' different positions within the social structure and their mutual possibilities to lay self-interest aside, together with (lack of) knowledge of each one's own position. For Okin, recourse to impartiality does not exclude empathy, the consideration of difference and care for others. Expounding these positions, the article offers a critical discussion of the value of impartiality and concludes that adherence to liberal premises restricts the potential of a feminist critique of justice.

KEYWORDS: Justice; gender; family; liberalism; feminist theory. 
GENRE ET FAMILLE DANS UNE SOCIÉTÉ JUSTE : ADHÉSION ET CRITIQUE À L'IMPARTIALITÉ DANS LE DÉBAT CONTEMPORAIN SUR LA JUSTICE

Flávia Biroli

L'article analyse le débat sur la justice et ses implications pour la critique féministe. L'accent est mis sur la discussion sur la nécessité d'un point de vue impartial pour la production de critères de justice 
dans les oeuvres de John Rawls et Susan Okin. La critique et l'adhésion d'Okin à l'approche de Rawls impliquent la défense, par l'auteur, de la conciliation entre l'appel à l'impartialité et la critique féministe, à la recherche de relations de genre plus justes. Chez Rawls, la justice dépend de la suspension d'intérêts et affections liées aux différentes positions des individus dans l'estructure sociale et du désentérêt mutuel, ainsi que le manque de connaissance de leur propre position. Pour Okin, l'utilisation de l'impartialité n'exclut pas l'empathie, la considération des différences et le soin avec les autres. Exposées ces positions, l'article discute critiquement la valeur de l'impartialité et conclut que l'adhésion aux buts libéraux limite le potentiel d'une théorie féministe de la justice.

MOTS-CLES: justice; genre; famille; libéralisme; théorie féministe. 